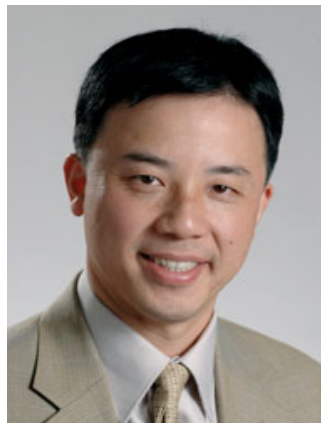

\section{Xiang Zhang to present Kavli Lecture at 2011 MRS Spring Meeting}

$\mathbf{X}^{\mathrm{in}}$ iang Zhang, the Ernest S. Kuh Chaired Professor at the University of California, Berkeley and the director of the National Science Foundation Nanoscale Science and Engineering Center (SINAM), has been selected for the Fred Kavli Distinguished Lectureship in Nanoscience. He will give a presentation at the 2011 Materials Research Society Spring Meeting on Monday, April 25, 7:00 pm at the San Francisco Marriott
Marquis. The title of his presentation is "Metamaterials - Creating properties that do not exist in nature."

Recent theory predicted a new class of photonic composite materials whose properties, derived by structure rather than chemical compositions, promise unprecedented electromagnetic properties that do not exist in nature, such as optical magnetism and negative refraction. Zhang will describe recent progress that demonstrated the physics. He will also discuss an array of new technologies, including a superlens for nanoscale lithography that could transform the next generation of nanomanufacturing and plasmon lasers that MRS could act as sources of coherent light on the molecular scale.

Zhang received his $\mathrm{PhD}$ degree from the University of California, Berkeley in 1996 and was on the faculties of the Pennsylvania State University and the University of California, Los Angeles (UCLA) prior to joining the Berkeley faculty in 2004. Zhang was elected to the National Academy of Engineering (NAE) in 2010. He has over 180 publications. His group's research in optical metamaterials was included in Time Magazine's Top 10 Scientific Discoveries in 2008.

\title{
Materials Research Societies in Singapore, China, and India presented inaugural trilateral conference on nanoscience
}

T he Materials Research Society of Singapore (MRS-S) and the Nanoscience Nanotechnology Initiative (NUSNNI) of the National University of Singapore (NUS) in association with the Chinese Materials Research Society (C-MRS) and the Materials Research Society of India (MRS-I) jointly organized the inaugural MRS-S Trilateral Conference on Advances in Nanoscience: Energy, Water \& Healthcare. B.V.R. Chowdari (MRS-S), Duan Weng (C-MRS), and Baldev Raj (MRS-I) cochaired the conference, which was held on August 11-13, 2010 at the Institute of Materials Research and Engineering (IMRE), Singapore, the supporting organization. Guest-of-honor Barry Halliwell, Deputy President of Research and Technology at NUS, emphasized the need for research collaboration between the three countries and congratulated the corresponding Materials Research Societies for bringing the scientists from these countries together.

Keynote speaker Seeram Ramakrishna (NUS) described the importance of the

theme and uniqueness of challenges in energy, water, and healthcare to the three countries and to the world overall. He described his work in the area of electrospun nanofibers, demonstrating how an understanding of the basic science quickly translates into commercial products. According to Ramakrishna, the ability of the electrospinning process to mass-produce continuous fibers with nanometer-scale diameter of different materials may provide solutions to global issues ranging from healthcare to environmental

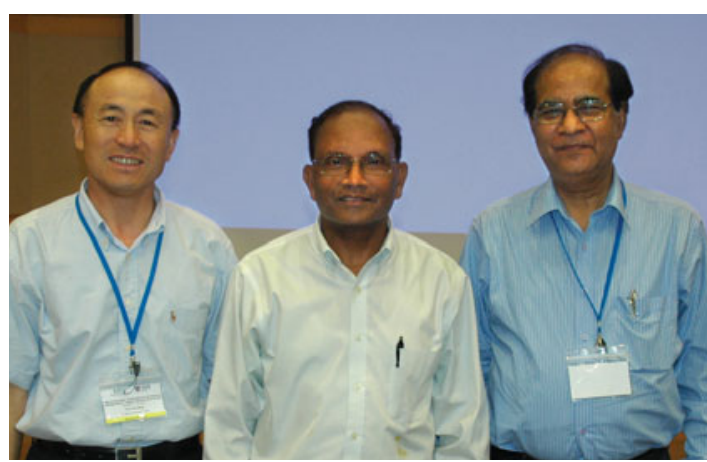

Co-chairs of the MRS-S Trilateral Conference on Advances in Nanoscience were (left to right) Duan Weng (Chinese MRS) of Tsinghua University, Beijing, China; B.V.R. Chowdari (MRS Singapore) of the National University of Singapore, Singapore; and Baldev Raj (MRS India) of the Indira Gandhi Center for Atomic Research, Kalpakkam, India. issues to energy.

Oral and poster presentations in the area of healthcare placed emphasis on the diagnosis of diseases and in the delivery of drugs and other biomolecules. To convert a laboratory discovery to a useful product for the benefit of society, many different skills will be required and the conference brought such experts together.
For example, after discoveries are made in biomarkers, it is essential for researchers to work with those who can fabricate and utilize the information.

The overriding message in the section of presentations on water was that challenges in water can unite the nations.

\section{MRS}

-MRS 
Presentations covered nanomaterialsbased sensors and devices, new membrane technologies incorporating biomimetic processes, and forward osmosis.

In the energy section, materials of importance and relevance to energy-conversion (e.g., solar-to-electrical, heat-toelectrical, and fuel-to-electrical), storage (e.g., in rechargeable batteries, such as hydrogen), and utilization (e.g., efficient light-emitting diodes, photocatalysts for pollutant-degradation, and water desalination), were discussed. In addition to the fundamental aspects, technologydevelopments, device fabrication, and performance-testing of them were reviewed and discussed.

The presentations demonstrated that the materials and technologies developed can be scaled up to quantities of relevance to the industry. The lessons learned from such experiences can re- sult in harnessing nanotechnology for societal applications.

The organizing Societies plan to establish a series of conferences to be rotated between the three countries with the interval of one year between the conferences. The next conference in this series will be held at the College of Materials Science and Engineering, Donghua University, Shanghai, China.

ICMAT 2011 to be held in Singapore

www.mrs.org.sg/icmat2011

$\mathbf{T}$ he International Conference on Materials for Advanced Technologies, organized by the Materials Research Society of Singapore (MRS-S), will be held on June 26-July 1, 2011, in Suntec,

\section{MRS} Singapore. The conference is chaired by B.V.R. Chowdari of the National University of Singapore.

Lim Hng Kiang, Minister for Trade and Industry of Singapore, will be the guest of honor at the inauguration ceremony. Plenary speakers include several Nobel laureates: Richard Schrock (Massachusetts Institute of Technology,
USA), Andre Geim (University of Manchester, UK), Ada Yonath (Weizmann Institute, Israel), K. von Klitzing (MaxPlanck-Institut für Festkörperforschung, Germany), and Albert Fert (CNRS, France).

Speakers in 40 symposia will address various topics including nanoscience and technology, energy and the environment, functional materials, bio/soft materials, imaging, and crystal growth and crystal technology. Industry workshops will be held on applied surface engineering and on the microelectronic process and package characterization and reliability analysis.

The conference also includes an exhibit, three theme lectures, an education forum and discussion, public lectures, and a conference banquet.

For more information, contact the conference secretariat, Meeting Matters International 1 Commonwealth Lane, \#06-23 One Commonwealth, Singapore 149544; tel. 65-6472-3108; fax 65-6472-3208; e-mail icmat2011@ meetmatt.net; and Web site www.mrs. org.sg/icmat2011.

\section{The 9th International Conference on Nitride Semiconductors to be held in} July 2011

$\mathbf{T}$ he 9th International Conference on Nitride Semiconductors (ICNS-9) will be held in Glasgow, Scotland on July 10-15, 2011, and continues the series of conferences providing an international forum for reporting advances in group-III nitride semiconductors such as gallium nitride and indium nitride.
Both fundamental research and applications will be covered, with oral and poster sessions focusing on topics such as epitaxial growth; bulk crystal growth; theory and simulation; optical and electronic devices (e.g., light-emitting diodes, lasers, and transistors); material characterization and development; and nanostructures involving nitride semiconductors. Confirmed keynote speakers include Umesh Mishra (University of California, Santa Barbara) and Hiroshi Amano (Meijo University).

For more details, visit www.icns9.org or contactinfo@icns9.org,44-141-3310123, or fax 44-141-331-0234.

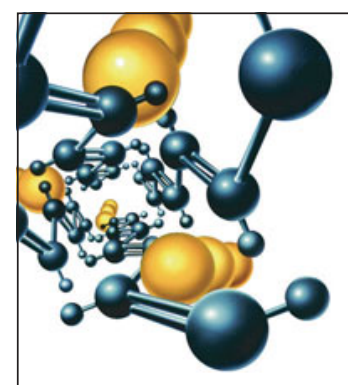

Organic Microelectronics \& Optoelectronics Workshop VII

July 18-20, 2011

Westin San Francisco Market Street, San Francisco, CA

For information on this Workshop, including speakers, schedules, lodging and registration

visit www.mrs.org/org-micro7 